\title{
POTENCIAL ENERGÉTICO DA CAMA DE AVIÁRIO PRODUZIDA NA REGIÃO SUDOESTE DO PARANÁ E UTILIZADA COMO SUBSTRATO PARA A PRODUÇÃO DE BIOGÁS
}

\author{
Alessandra Buss Tessaro" \\ Amarildo Antonio Tessaro** \\ Maurício Pereira Cantão*** \\ Maria Alessandra Mendes ${ }^{* * * *}$
}

RESUMO: O processo da criação confinada gera resíduos que causam problemas ambientais e requerem um manejo diferenciado, pois pode gerar um alto impacto ambiental. Faz-se necessária uma nova disposição para os resíduos produzidos. Este trabalho avaliou o potencial energético da cama de aviário produzida na região Sudoeste do Paraná, utilizada como substrato para a produção de biogás. Foi realizada uma pesquisa qualitativa, quantitativa e exploratória onde se levantou dados em bibliografias específicas sobre o assunto e a caracterização da produção avícola da região Sudoeste do Paraná. A biomassa de frango produzida foi caracterizada quimicamente e posteriormente avaliada em três tratamentos, para se determinar a capacidade de produzir biogás. Os resultados mostraram que o Sudoeste do Paraná mantém um plantel de frangos de corte de 39.173.367 cabeças/ano em 38 municípios, gerando assim 51.219,17 toneladas de biomassa na forma de cama de aviário/ ano. Essa biomassa é constituída de nitrogênio, fósforo, potássio, cálcio, magnésio e sulfatos. A biomassa se mostrou capaz de produzir biogás nos três sistemas de tratamento avaliados sendo que o tratamento dois se mostrou mais viável. O biofertilizante produzido se mostrou rico em macro e micronutrientes, destacando-se nitrogênio, fósforo, potássio, cálcio, magnésio, sódio, ferro, boro, cobre, zinco e manganês. $\mathrm{O}$ pH do biofertilizante variou de 6,58 a 8,02. Com isso, pode-se concluir que o uso da biomassa de cama de aviário é uma alternativa viável na produção de biogás, capaz de substituir os combustíveis tradicionais e a energia elétrica consumida nas propriedades avícolas da região Sudoeste do Paraná.

PALAVRAS-CHAVE: Avicultura; Biodigestores; Biofertilizante; Biogás; Biomassa.

\footnotetext{
"Tecnóloga em Saneamento Ambiental e Engenheira Civil; Doutoranda em Ciência e Engenharia de Materiais pela Universidade Federal de Pelotas (UFPel); E-mail: alessandrabuss@gmail.com

*** Engenheiro Agrônomo; Mestre em Desenvolvimento de Tecnologia pelo Instituto de Tecnologia para o Desenvolvimento; Docente na União de Ensino do Sudoeste do Paraná (UNISEP).

*** Doutor em Física; Docente no Programa de Pós-Graduação em Desenvolvimento de Tecnologia no Instituto de Tecnologia para o Desenvolvimento.

***** Engenheira Civil; Mestre em Engenharia de Recursos Hídricos e Ambiental. Coordenadora dos cursos de Engenharia Civil e Engenharia de Produção na Faculdade Integrado de Campo Mourão.
} 


\section{ENERGY CAPACITY OF BROILER LITTER USED AS A SUBSTRATE FOR BIOGAS PRODUCTION IN THE SOUTHWESTERN REGION OF THE STATE OF PARANÁ, BRAZIL}

ABSTRACT: The breeding of confined broilers produces wastes that cause environmental problems. They require different management procedures since they may generate great environmental impact and consequently disposal for the residues produced. Current paper assessed the energy capacity of broiler litter used as a substrate for the production of biogas in the southwestern region of the state of Paraná, Brazil. A qualitative, quantitative and exploratory research was undertaken for data in specific bibliographies on the subject and the characterization of poultry production in the region. Poultry biomass was characterized chemically and later evaluated in three treatments to determine the capacity for biogas production. Results showed that the southwestern region of the state of Paraná produces 39,173,367 broilers/ year in 38 municipalities, with 51,219.17 tons of biomass in the form of broiler litter/ year. The biomass, comprising nitrogen, phosphorus, potassium calcium, magnesium and sulfates, produces biogas in the three treatment systems under analysis, although the second treatment was the most viable. The biofertilizers, with $\mathrm{pH}$ between 6.58 and 8.02 , proved to be rich in macro- and micro-nutrients, mainly nitrogen, phosphorus, potassium calcium, magnesium, sodium, iron, boron, copper, zinc and manganese. Biomass from broiler litter may be a viable alternative in the production of biogas which will be capable of replacing traditional fuel and electric energy in poultry-breeding farms in the region.

KEY WORDS: Poultry Breeding; Biodigesters; Biofertilizer; Biogas; Biomass.

\section{INTRODUÇÃO}

É crescente a busca por geração de energia limpa, pois vem de fontes renováveis e não libera substâncias poluentes ao meio ambiente durante seu processo de geração. As pesquisas sobre sustentabilidade têm tido cada vez mais sucesso e a preocupação com a emissão de gases e redução da utilização de recursos hídricos, bem como o destino adequado aos resíduos gerados vêm aumentando (DIEDRICH; ROCHA; LOPES, 2012).

A economia da região Sudoeste do Paraná é bastante dependente da agricultura e suas indústrias derivadas. Existem, instaladas na região, diversas empresas 
relacionadas ao agronegócio, algumas de expressão nacional como a Sadia, Anhambi, Diplomata e Coasul (Cooperativa Agrícola Sudoeste Ltda.), onde a principal atividade desse setor agroindustrial é a criação de 37.173.367 aves/ano em sistema de integração (AMSOP, 2010).

A avicultura é uma das atividades que mais vem crescendo no Brasil, que é considerado o terceiro maior produtor de aves de corte, ficando atrás somente dos Estados Unidos e da China. A cama é o principal subproduto na avicultura, e é normalmente reutilizada para reduzir o custo de produção e a poluição ambiental. Apesar da possibilidade de reutilização, há poucas informações sobre suas características e padrões de qualidade nos diferentes lotes de reutilização. A cama normalmente é composta por um material produzido em abundância na região e esse material possui sempre uma parte muito lignificada e de difícil degradação (COSTA, 2012).

A partir dos dados fornecidos pela Associação dos Municípios do Sudoeste do Paraná, verifica-se que dos 42 municípios formadores da região Sudoeste do Estado, 38 apresentam os dados referentes das populações de cabeças de frangos criadas anualmente nesta região. Desses 38 municípios percebe-se que a maior população de frangos encontra-se no município de Dois Vizinhos com 6.524.000 cabeças de frango, seguido de Francisco Beltrão com 4.184 .860 cabeças. Com esses dados levantados pode-se calcular o potencial de cama de aviário produzida por essa população de frangos levando em consideração a permanência desses frangos por um período de 35 dias.

A aplicação dos dejetos dessa atividade no solo, sem um adequado tratamento, pode provocar eventos impactantes no ambiente, degradação dos ecossistemas aquáticos e terrestres, e gerar riscos à saúde humana, sobretudo pela grande carga orgânica e pela enorme quantidade de nitrogênio e fósforo presente nos dejetos (AIRES et al., 2009).

Uma alternativa de energia limpa para reutilização desse resíduo é o biogás, que substitui o gás natural, sendo utilizado na geração de energia elétrica, mecânica e térmica, produzindo poucos poluentes na atmosfera que, além de ter como subproduto o biofertilizante, agrega valor aos restos da produção agrícola (SEBRAE, 2008).

A abrangência desse estudo se restringe à área de avicultura representada pela região Sudoeste do Estado do Paraná, que concentra, juntamente com o Oeste 
do Estado de Santa Catarina, a maior parte do rebanho de aves da região Sul do Brasil. Assim sendo, os resultados alcançados por esta pesquisa terão em vista a possível aplicação voltada para esta região. Nesse contexto, o presente estudo avaliou o potencial energético da cama de aviário produzida na região Sudoeste do Paraná utilizada como substrato para a produção de biogás.

\section{MATERIAL E MÉTODOS}

Foram levantados dados sobre a produção de frangos em 42 municípios da região Sudoeste do Paraná, como número de cabeças de frango por ano, bem como as quantidades de cama de aviário produzidas na região.

Para determinação da composição química da cama de aviário, foram coletadas 45 amostras em 45 propriedades distribuídas nos 42 municípios do Sudoeste do Paraná. As amostras, pesando $2,5 \mathrm{~kg}$, foram armazenadas em um único tambor, onde foram homogeneizadas e dessa mistura foram coletadas três sub-amostras. Esse material foi identificado e transportado ao Laboratório de Solos da Universidade Tecnológica Federal do Paraná (UTFPR) - Campus de Pato Branco (PR), onde foi caracterizado quimicamente.

Para tanto, as amostras foram digeridas, utilizando-se o digestor Digesdahl@ fornecido pela Hach, que promove a digestão total da matéria orgânica à base de ácido sulfúrico $\left(\mathrm{H}_{2} \mathrm{SO}_{4}\right)$. Com o extrato formado foram determinados os teores de nitrogênio, fósforo, potássio, cálcio, magnésio, cobre, manganês, zinco, sódio, segundo procedimento estabelecido por Bataglia (1983).

Para a determinação de nitrogênio foi utilizado o microdestilador Kjeldahl, conforme metodologia descrita por Silva (1983). Os teores de fósforo foram determinados pelo método colorimétrico utilizando-se espectrofotômetro marca Fento, conforme metodologia descrita por Malavolta, Vitti e Oliveira (1991).

A concentração de cálcio, magnésio, potássio, cobre, ferro, manganês, zinco e sódio foi determinada por absorção atômica através de um equipamento modelo Optima 2000 GBC 932 AA, acoplado a um computador contendo o software GBCAA. Nele, as amostras digeridas são comparadas com padrões segundo o elemento que se esteja analisando. As análises químicas foram realizadas com amostras no 
Laboratório de Solos da UTFPR - Campus de Pato Branco (PR).

A capacidade de produção de biogás a partir de camas de frangos foi avaliada pelo processo de biodigestão anaeróbia em ensaio com operação batelada, utilizando para isso um biodigestor do tipo indiano com capacidade para 60 litros, abastecido de uma única vez em cada um dos experimentos, mantendo-se em fermentação pelo período conveniente, sendo o material descarregado posteriormente após o término do período efetivo de produção de biogás. Todos os ensaios foram realizados seguindo a metodologia descrita por Seixas (1980).

As camas de frango foram obtidas de um galpão de frango convencional com $1200 \mathrm{~m}^{2}$ instalado na propriedade rural localizada nas coordenadas geográficas 25044'06" S e 5304'52" W do município de Dois Vizinhos (PR), onde se fez o reaproveitamento da cama de 03 lotes de frangos criados por 40 dias, em média.

O substrato utilizado na forração do piso era de serragem de pinus e a espessura da cama inicial era de aproximadamente $12 \mathrm{~cm}$, volume incrementado com a colocação de novos substratos para aproveitamento nos demais ciclos de produção sob a mesma cama. Porém, com a finalidade experimental foram retiradas camas do terceiro lote, o qual foi utilizado no experimento. Foi abastecido um biodigestor indiano em batelada. Foram realizados três ensaios em três repetições. Esse biodigestor foi desenvolvido pela Prof. Dra. Maria Alessandra Mendes, do LACTEC, apresentava um cunho didático e foi adaptado para a aplicação da metodologia deste trabalho. As características do biodigestor utilizado estão apresentadas na Figura 1.



Figura 1. Modelo biodigestor indiano em batelada utilizado no processo. Onde: 1 - Entrada do substrato; 2 - Depósito para manter o fluxo regular; 3 - Condutor do fluxo; 4 - Câmara de fermentação; 5 - Câmara de depósito do gás; 6 - Válvula saída do gás; 7 - Saída do material fermentado; 8 - Registro de controle do fluxo do material; 9 - Registro para a limpeza. 
Os ensaios foram realizados durante os meses de maio de 2008 a março de 2010 , com temperatura mínima de $15^{\circ} \mathrm{C}$ e máxima de $37^{\circ} \mathrm{C}$, segundo o Sistema Meteorológico do Paraná (Simepar). Neste perído foram realizados os ensaios descritos abaixo:

1ำ Ensaio: Cama de Frango + Água - $[\mathrm{CF}+\mathrm{A}]_{1 ;}$ Período de realização: maio a setembro de 2008; $30 \mathrm{~kg} C F+30 \mathrm{~kg} \mathrm{~A}$

2o Ensaio: Cama de Frango + Água - $[\mathrm{CF}+\mathrm{A}]_{2 ;}$ Período de realização: setembro de 2008 a maio de $2009 ; 15 \mathrm{~kg} \mathrm{CF}+45 \mathrm{~kg} \mathrm{~A}$

$3^{\mathrm{o}}$ Ensaio: Descrição dos tratamentos; Período de realização: setembro de 2009 a março de 2010.

T1) Cama de Frango + Biofertilizante + água, $(\mathrm{CF}+\mathrm{B}+\mathrm{A})$ - sendo: 28,25 $\mathrm{kg}$ de água $+28,25 \mathrm{~kg}$ de biofertilizante $+3,5 \mathrm{~kg}$ de cama;

T2) Cama de Frango + Biofertilizante $(\mathrm{CF}+\mathrm{B})$ - sendo: $56,5 \mathrm{~kg}$ de biofertilizante $+3,5 \mathrm{~kg}$ de cama;

T3) Cama de Frango + Água $(\mathrm{CF}+\mathrm{A})-$ sendo: $56,5 \mathrm{~kg}$ de água $+3,5 \mathrm{~kg}$ de cama.

O biofertilizante utilizado nesses ensaios se caracteriza como o inóculo adicionado ao processo, visando viabilizar o início do processo de fermentação em um menor espaço de tempo, e foi obtido de processos fermentativos anteriores com cama de aviário, sendo constituído de uma flora microbiana oriunda desses processos fermentativos.

Os experimentos foram conduzidos por um período de 56 dias e o volume do biogás produzido foi observado através de um êmbolo a cada 7 dias, onde os valores foram anotados e as médias de biogás produzido foram quantificadas. A quantificação do biogás foi realizada conforme se observava o acúmulo na produção, com acompanhamento realizado diariamente.

A análise de macro e micronutrientes foi realizada em três amostras líquidas dos afluentes e em três amostras líquidas dos efluentes, para quantificação dos minerais presentes nas mesmas. Determinou-se os teores de nitrogênio, fósforo, potássio, cálcio, magnésio, cobre, manganês, zinco e sódio (BATAGLIA, 1983). 


\section{RESULTADOS E DISCUSSÃO}

Considerando que a população de frango da região Sudoeste é de 39.173.367 cabeças (AMSOP, 2010), aplica-se a seguinte fórmula: Total de cama de aviário = população de frangos ' quantidade de esterco ' $0,5 \mathrm{~kg} /$ cabeça.

Assim, Total de cama de aviário $=39.173 .367^{\prime} 2,615^{\prime} 0,5=51.219 .177,35$ kg de cama de aviário produzidos na região Sudoeste do Paraná. Esse valor equivale a 51.219,177 toneladas de cama de aviário/ano. Com esses dados será possível determinar o potencial energético da região Sudoeste do Paraná, baseados na biomassa de cama de aviário. A Figura 2 mostra a disposição da cama de aviário em uma das propriedades analisadas.

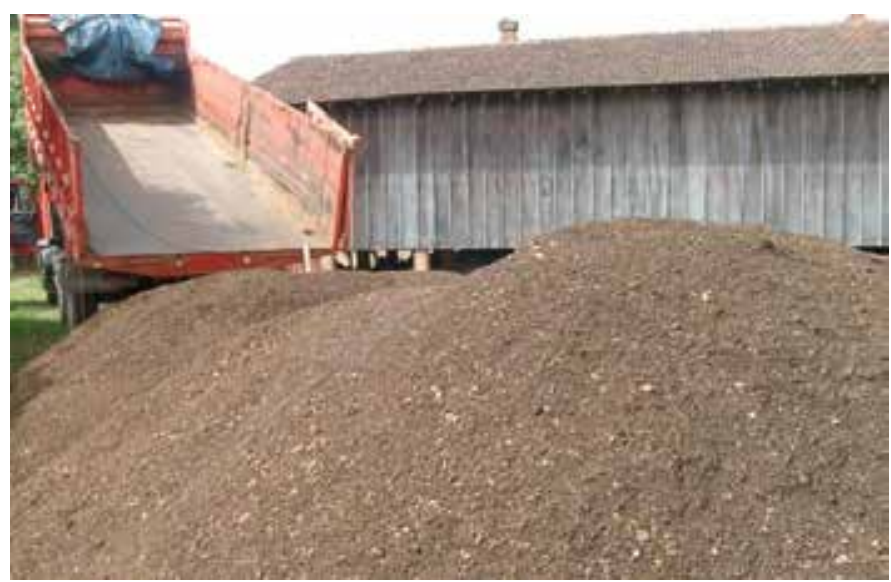

Figura 2. Cama de aviário produzida nos diversos ambientes de criação de frangos da região Sudoeste do Paraná

Os resultados obtidos mostraram que os dois modelos de biodigestor dimensionados e caracterizados como ensaios $[\mathrm{CF}+\mathrm{A}]_{1}$ e $[\mathrm{CF}+\mathrm{A}]_{2}$ se mostraram inviáveis do ponto de vista dos processos de produção de biogás. Esses dados podem ser observados na Tabela 1. 
Tabela 1. Produção a cada 7 dias $\left(\mathrm{m}^{3} / \mathrm{kg}\right.$ de biomassa) de Biogás para o Biodigestor tipo Batelada Abastecido com Cama de Frango e Acrescido de Água [CF+A].

\begin{tabular}{ccc}
\hline Dias de processo & {$[\mathbf{C F}+\mathbf{A}]_{1}$} & {$[\mathbf{C F}+\mathbf{A}]_{2}$} \\
\hline 0 & 0,0 & 0,0 \\
7 & 0,0123 & 0,0093 \\
14 & 0,0172 & 0,0134 \\
21 & 0,0234 & 0,0212 \\
\hline
\end{tabular}

O que se pode observar por esses ensaios é que a digestão anaeróbia mostrou-se lenta no início para a produção de biogás, apresentando assim uma fase lag muito longa, com tempos superiores a 15 dias. Dessa maneira essas duas bateladas foram encerradas aos 21 dias, com produções de 0,0234 e $0,0212 \mathrm{~m}^{3}$ de biogás nos tratamentos $[\mathrm{CF}+\mathrm{A}]_{1}$ e $[\mathrm{CF}+\mathrm{A}]_{2}$ Deve-se destacar que esse ensaio passou por apenas duas repetições e, assim, sobre ele não foram aplicados programas estatísticos.

O ensaio caracterizado como número 3, mostrou-se viável, e capaz de ser utilizado como modelo no uso da biomassa formada basicamente com cama de aviário. Dessa maneira, a discussão deste trabalho se baseia neste ensaio onde se adotaram três tratamentos característicos. Os potenciais médios de produção de biogás no ensaio 3 estão apresentados na Tabela $2, \mathrm{em} \mathrm{m}^{3}$ de biogás por $\mathrm{kg}$ de matéria seca.

Tabela 2. Produção a cada 7 dias $\left(\mathrm{m}^{3} / \mathrm{kg}\right.$ de biomassa) de Biogás no Biodigestor tipo Batelada Abastecido com Cama de Frango Diluída em Biofertilizante de Aves e Água.

(continua)

\begin{tabular}{cccc}
\hline \multirow{2}{*}{ Dias de processo } & $\mathbf{C F + B + A}$ & $\mathbf{C F}+\mathbf{B}$ & $\mathbf{C F}+\mathbf{A}$ \\
\cline { 2 - 4 } & Vol. & Vol. & Vol. \\
\hline 0 & 0,0 & 0,0 & 0,0 \\
7 & 0,0482 & 0,1242 & 0,0161 \\
14 & 0,1684 & 0,1875 & 0,0183 \\
21 & 0,3682 & 0,3745 & 0,1285 \\
28 & 0,3823 & 0,5289 & 0,1546 \\
35 & 0,4230 & 0,5529 & 0,1573 \\
42 & 0,4554 & 0,5593 & 0,0862 \\
49 & 0,4420 & 0,5293 & 0,0558 \\
\hline
\end{tabular}




\begin{tabular}{cccc}
\hline & & & \\
& & & (conclusão) \\
Média* & 0,3251 & 0,4286 & 0,0265 \\
Total do período & $0,3264 \pm 0,0243 \mathrm{~B}$ & $0,4106 \pm 0,0128 \mathrm{~A}$ & $0,0804 \pm 0,0023 \mathrm{C}$ \\
\hline Cinética de ordem 2 & $\mathrm{y}=-0,0004 \mathrm{x}^{2}+$ & $\mathrm{y}=-0,0004 \mathrm{x}^{2}+$ & $\mathrm{y}=-0,0002 \mathrm{x}^{2}+$ \\
& $0,0312 \mathrm{x}-0,159$ & $0,0352 \mathrm{x}-0,1496$ & $0,0142 \mathrm{x}-0,0904$ \\
\hline
\end{tabular}

* Médias seguidas da mesma letra na horizontal não diferem entre si pelo Teste de Tukey, ao nível de $5 \%$ de significância.

De acordo com os resultados obtidos na Tabela 2 e demonstrados na Figura 3, notaram-se produções superiores de biogás quando abastecidos com cama de frango + biofertilizante em relação aos biodigestores abastecidos com cama de frango + biofertilizante + água e cama de frango + água, onde se verifica que a mistura que menos produziu biogás foi a mistura cama de frango + água (T-3). Esse comportamento foi observado durante todo o processo.

Comparando-se as médias obtidas nos três tratamentos, verifica-se que o tratamento T2 se mostrou superior ao nível de 5\% pelo Teste de Tukey, na produção de biogás, durante o período sobre os outros dois tratamentos (T1 e T3), pois os valores médios foram de $0,4106 \pm 0,0128,0,3264 \pm 0,0243$ e $0,0804 \pm 0,0023 \mathrm{~m}^{3} \mathrm{de}$ biogás por kg de biomassa adicionada ao processo, respectivamente para cada uma das avaliações realizadas. Os dados relativos às produções volumétricas de biogás estão apresentados nas Figuras 3 e 4.

Considerando os resultados obtidos com os tratamentos, verifica-se que o tratamento $\mathrm{CF}+\mathrm{B}$ produziu maior quantidade de biogás durante os 56 dias e apresentou um pico de produção de biogás aos 42 dias e observou-se uma queda na produção a partir dos 49 dias, mantendo essa produção em queda até o final do processo, sendo que ao término apresentou uma cinética igual a $\mathrm{y}=-0,0004 \mathrm{x}^{2}+$ $0,0312 x-0,159$ com coeficiente de correlação $R^{2}=0,9641$. 


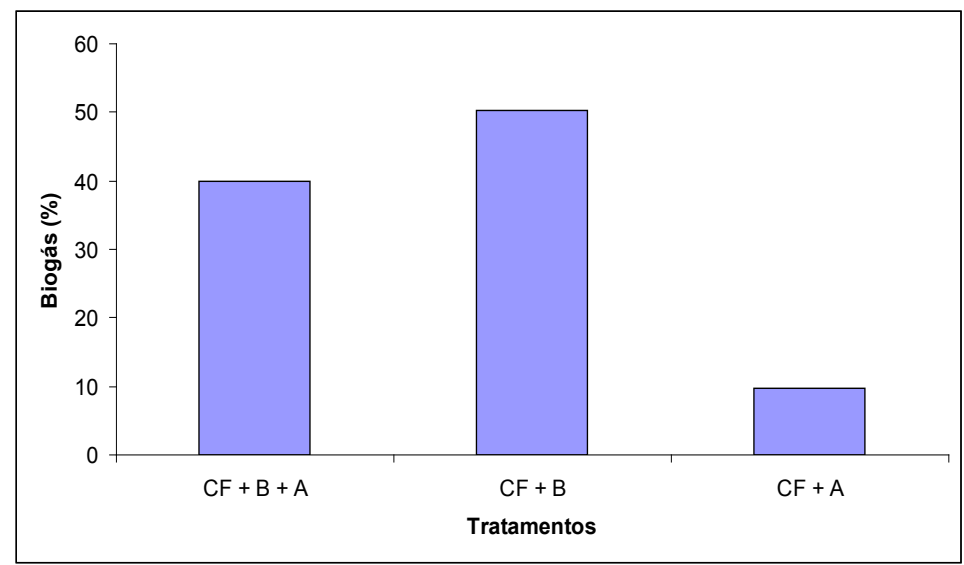

Figura 3. Produção acumulada de biogás para cada tratamento durante o processo

Deve-se destacar que a variável tempo foi importante nesta análise, pois os volumes de biogás produzidos foram aumentando no decorrer dos tempos analisados. Isso se torna importante, pois o conhecimento da faixa de maior produção de biogás em um determinado tempo é fundamental para o dimensionamento do aproveitamento do biogás gerado.

Suzuki et al. (2012) não tiveram uma produção inicial rápida de biogás, mas os dados obtidos em seu experimento se mostraram constantes e em crescimento aos 70 dias. Explicaram o fato devido à cama de aviário ser heterogênea e possuir seus componentes agrupados em substâncias de rápida e de lenta degradação. Os componentes de lenta degradação são os da madeira, como lignina, celulose e hemicelulose.

Aires (2009) encontrou em seu trabalho que a produção de biogás dos tratamentos sem a separação de sólido da cama de aviário obtém uma produção mais lenta em sua fase inicial logo após entrando em declínio e voltando a subir. Já o tratamento com separação dos sólidos possui início de produção de biogás mais demorado, mas se mantém em crescimento mais estável.

O que pode ser observado é que os outros dois tratamentos apresentaram o mesmo comportamento, porém com início de produção um pouco mais tardio, onde o tratamento $\mathrm{CF}+\mathrm{B}+\mathrm{A}$ somente alcançou os volumes verificados no tratamento $\mathrm{CF}+\mathrm{B}$ no tempo próximo aos 14 dias. Sendo assim, as cinéticas referentes 
aos tratamentos $\mathrm{CF}+\mathrm{B}+\mathrm{A}$ e $\mathrm{CF}+\mathrm{A}$, que representam o comportamento de cada tratamento e estão expressas por meio de curvas de ajustes poligonais, foram $\mathrm{y}=$ $-0,0004 \mathrm{x}^{2}+0,0312 \mathrm{x}-0,159$ com $\mathrm{R}^{2}=0,9641$ e $\mathrm{y}=-0,0002 \mathrm{x}^{2}+0,0142 \mathrm{x}-0,0904$, com um $\mathrm{R}^{2}=0,7944$, respectivamente, observando-se que o tratamento que menos produziu biogás foi o $\mathrm{CF}+\mathrm{A}$.

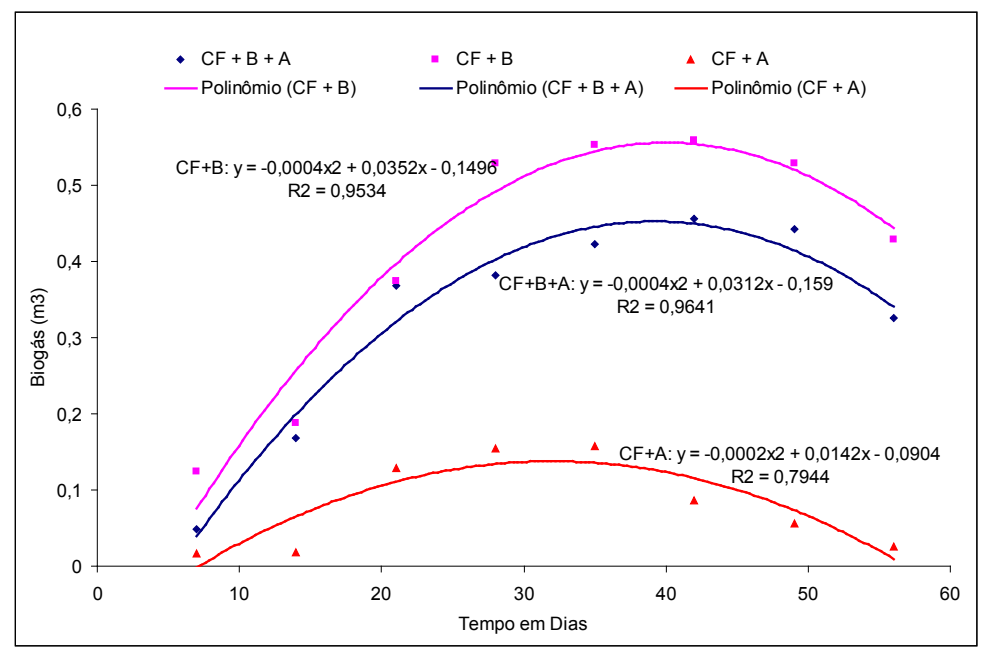

Figura 4. Cinética do comportamento polinomial de ordem 2 de cada um dos sistemas durante 0 processo. Equações seguidas de coeficiente de determinação para cada tratamento $\mathbf{R}^{2}$.

O coeficiente de determinação, $R^{2}$, é a porcentagem da variação da variável dependente explicada pela variável independente. Deve-se esclarecer que quanto mais próximo de 1,0 for o $\mathrm{R}^{2}$ menor será a diferença entre os dados reais e os pontos na curva de ajuste de comportamento ou a cinética do comportamento da variável observada.

Em uma análise geral, referente aos valores totais de produção de biogás, percebe-se que os volumes dos três tratamentos chegaram a 2.611,20 +3.284,80 $+0,643,20 \mathrm{~m}^{3}$, respectivamente para $\mathrm{CF}+\mathrm{B}+\mathrm{A}, \mathrm{CF}+\mathrm{B}$ e $\mathrm{CF}+\mathrm{A}$, totalizando aproximadamente $6.540 \mathrm{~m}^{3}$. Calculando as porcentagens de cada um dos tratamentos em relação ao volume total de biogás produzido nos três experimentos, verifica-se que o tratamento $\mathrm{CF}+\mathrm{B}+\mathrm{A}$ produziu $40 \%$, o tratamento $\mathrm{CF}+\mathrm{B}$ produziu $50 \%$ e o tratamento $\mathrm{CF}+\mathrm{A}$ produziu $10 \%$ do biogás. 
Os valores indicam a influência do período nos potenciais de produção de biogás encontrados neste experimento e são semelhantes aos estudos de Ortolani, Benincasa e Lucas Junior (1991), que encontraram diferença altamente significativa para as médias dos potenciais de produção de biogás entre três ensaios.

Por meio da visualização do comportamento nas curvas de ajustes referentes aos volumes de biogás dos tratamentos é possível planejar um sistema que atenda determinada demanda de energia. A antecipação dos picos de produção de biogás do tratamento $\mathrm{CF}+\mathrm{B}$ pode ser claramente observada na Tabela 2. Este fato ocorreu, provavelmente, devido à adição da presença do biofertilizante em associação com a cama de frango acelerando as fases de biodigestão anaeróbia e aumentando a velocidade de produção de biogás.

Para planejar a produção de biogás para geração de energia deve-se considerar as áreas com produção de biogás mais expressivas nos desenhos das curvas para que não falte energia quando a demanda por esta for alta. Por exemplo, utilizando a produção de biogás através da biodigestão anaeróbia de cama de frango, deve-se fazer um planejamento adequado, levando em consideração a fase de maior produção de biogás em relação aos lotes de frango, aumentando assim a viabilidade do biodigestor e a geração de energia.

Nessas condições, verifica-se que o melhor tratamento foi aquele em que se utilizou cama de frango associada ao biofertilizante, seguido do tratamento onde se utilizou cama de frango associada ao biofertilizante de bovino, mais água. Os menores resultados foram observados no terceiro tratamento, cuja mistura foi cama de frango e água.

No trabalho de Costa (2012), o tratamento que recebeu cama de frango com biofertilizante sem a separação de sólidos apresentou os maiores resultados, embora o biofertilizante tenha atuado como importante inóculo favorecendo a produção de biogás; a fração sólida demorou a ser digerida, pois na cama do primeiro lote há maior concentração de matéria orgânica digerível, consequentemente, há uma atuação mais significativa de bactérias.

Sendo a cama de frango um resíduo produzido em intervalos de tempo, ou seja, a disponibilidade não é contínua devido ao modo de produção e, considerando suas características físicas e químicas como alto teor de sólidos, baixa umidade 
e tamanho das partículas, o tipo de biodigestor ideal, pelas suas características de desenho e desempenho, para uma perfeita digestão anaeróbia da biomassa, é o biodigestor batelada, podendo este ser manejado em forma de bateria ou sequencialmente. A desvantagem do manejo em forma de bateria está relacionada à velocidade de fermentação da cama, que é lenta, dificultando o aproveitamento do biogás (MAGALHÃES, 1986).

Pode ser necessário que a cama tenha que sofrer um pré-tratamento antes de ser adicionada ao biodigestor; o mais indicado seria uma moagem, pois as partículas de maravalha podem ser muito grandes e isso pode diminuir a eficiência das atividades dos microrganismos. Observando-se o teor de umidade da cama se faz necessária a adição de água nesta para diminuição do teor de sólidos e diluição do conteúdo (SANTOS, 1992).

Considerando que os três tratamentos avaliados neste trabalho apresentaram produção de biogás, sendo o tratamento T2 o mais viável, onde o volume de biogás produzido no período foi de aproximadamente $3,3 \mathrm{~m}^{3} / \mathrm{kg}$ de biomassa de cama de aviário, pode-se determinar a capacidade energética da cama de aviário produzida na região Sudoeste do Paraná.

Nesse contexto, para cada kg de biomassa de cama de frango tem-se 2,611 $\mathrm{m}^{3}$ de biogás utilizando o sistema cama de frango + biofertilizante + água; 3,284 $\mathrm{m}^{3}$ de biogás no sistema cama de frango + biofertilizante; e $0,643 \mathrm{~m}^{3}$ de biogás no sistema cama de frango mais água.

Dessa forma, para o cálculo da capacidade em produzir biogás da região Sudoeste do Paraná, levando em consideração o gás produzido por kg de cama de frango, será utilizado apenas o tratamento T3 do terceiro ensaio cuja composição foi cama de aviário + água.

Considerando que nos três experimentos, dimensionados e monitorados, observaram-se valores variáveis entre 0,643 a $3,284 \mathrm{~m}^{3} / \mathrm{kg}$ de cama de aviário, nos cálculos que serão realizados, serão usados os menores valores levando em consideração que inúmeras variáveis podem interferir no processo de produção de biogás, levando à obtenção de valores inferiores aos obtidos neste trabalho, que foi de 3,284 $\mathrm{m}^{3} / \mathrm{kg}$ de cama de aviário.

Assim, a CPB (capacidade de produzir biogás) $=0,643 \mathrm{~m}^{3} / \mathrm{kg}$ de cama de 
aviário ’ $51.219 .177 \mathrm{~kg}$ de cama de aviário nos 38 municípios da região Sudoeste do Paraná/ano, tem-se um volume de $32.933 .931 \mathrm{~m}^{3} /$ ano de biogás, que poderiam ser produzidos em toda a região Sudoeste do Paraná, utilizando apenas o sistema cama de frango + água. Caso considerarmos os três tratamentos, os volumes seriam muito superiores, pois a produção de biogás nos tratamentos 1 e 2 foram significativamente maiores que o tratamento 3 . Esses dados podem ser observados na Tabela 3.

Tabela 3. Capacidade da região sudoeste em produzir Biogás.

\begin{tabular}{cc}
\hline Tratamento & Volumes totais $\left(\mathbf{m}^{3} / \mathbf{a n o}\right)$ \\
\hline T1 & 136.344 .271 \\
T2 & 168.203 .177 \\
T3 & 32.933 .931 \\
\hline
\end{tabular}

Levando em consideração os valores obtidos e utilizando o poder calorífico do biogás produzido, pode-se estimar a economia no uso de outros combustíveis, usando a equivalência de 0,61 litros de gasolina; 0,58 litros de querosene; 0,55 litros de óleo diesel; 0,45 litros de gás de cozinha; 1,5 quilos de lenha; e 0,79 litros de álcool hidratado para cada $\mathrm{m}^{3}$ de biogás. Dados referentes a essa economia encontram-se na Tabela 5.

Deve-se destacar que, de acordo com Silva et al. (2005), o biogás normalmente é armazenado a baixa pressão e pode ser utilizado em equipamentos para geração de calor como fogões, fornalhas, campânulas de aquecimento, etc. Boa parte dos equipamentos em operação com biogás ainda está empiricamente adaptada, porém, com o aumento no número de biodigestores, fomentados por projetos relacionados ao mecanismo de desenvolvimento limpo (MDL), espera-se rápida evolução na qualidade dos queimadores e motores ofertados no mercado. 
Tabela 4. Uso equivalente do Biogás em relação a outras fontes.

\begin{tabular}{cccc}
\hline Economia & $\begin{array}{c}\text { T1 } \mathbf{C F}+\mathbf{B}+\mathbf{A} \\
\mathbf{1 3 6 . 3 4 4 . 2 7 1} \mathbf{~ m}^{3} / \mathbf{a n o}\end{array}$ & $\begin{array}{c}\text { T2 } \mathbf{C F}+\mathbf{B} \\
\mathbf{1 6 8 . 2 0 3 . 1 7 7} \mathbf{~ m}^{3} / \mathbf{a n o}\end{array}$ & $\begin{array}{c}\mathbf{T 3} \mathbf{- C F}+\mathbf{A} \\
\mathbf{3 2 . 9 3 3 . 9 3 1} \mathbf{~ m}^{3} / \mathbf{a n o}\end{array}$ \\
\hline Gasolina - L & 83.170 .005 & 102.603 .937 & 20.089 .697 \\
Querosene - L & 79.079 .677 & 97.557 .842 & 19.101 .679 \\
Óleo diesel - L & 74.989 .349 & 92.511 .747 & 18.113 .662 \\
Gás de cozinha - L & 61.354 .921 & 75.691 .429 & 14.820 .268 \\
Lenha - kg & 204.516 .406 & 252.304 .765 & 49.400 .896 \\
Álcool hidratado - L & 107.711 .974 & 132.880 .509 & 26.017 .805 \\
\hline
\end{tabular}

Os dados apresentados na Tabela 4 mostram a viabilidade do uso da cama de aviário na produção de biogás, pois a matéria-prima para a sua produção está disponível em toda a região Sudoeste do Paraná. A apresentação dos três tratamentos mostrou-se importante, pois nos três sistemas foi possível produzir quantidades expressivas do biogás, podendo com isso substituir principalmente os combustíveis não renováveis como os derivados do petróleo.

A geração de empregos tem sido reconhecida como uma das maiores vantagens das energias renováveis, em especial a biomassa. Isso porque a geração de empregos diretos e indiretos promove um ciclo virtuoso de aumento dos níveis de consumo e qualidade de vida, inclusão social, geração de mais atividades econômicas, fortalecimento da indústria local, promoção do desenvolvimento regional e a redução do êxodo rural. Diante desse panorama, a produção de biomassa é uma atividade que envolve muitos empregos, porém com mão de obra barata.

Utilizar a cama de aviário para produzir a própria energia é de grande valia e pode ajudar na redução da poluição ambiental, a manutenção do homem no campo e melhorias na sua qualidade de vida. Costa (2012) afirma que a reciclagem de resíduos e utilização de fontes renováveis de energia são tecnologias que se tornam atrativas tanto ambientalmente como socialmente, pois possibilitam a criação de fontes de suprimento descentralizadas e até em pequena escala, e isto torna-se fundamental para o desenvolvimento sustentável dos países.

As características químicas da cama de aviário produzida na região Sudoeste do Paraná estão apresentadas na Tabela 5 e na Figura 5. 
Tabela 5. Composição Química da Cama de Aviário obtida de 45 amostras da região Sudoeste do Paraná em comparação com a literatura.

\begin{tabular}{ccccccc}
\hline \multicolumn{7}{c}{ g/kg de matéria seca* } \\
\hline $\mathrm{AM}$ & $\mathrm{N}$ & $\mathrm{P}$ & $\mathrm{K}$ & $\mathrm{Ca}$ & $\mathrm{Mg}$ & $\mathrm{SO}_{4}$ \\
1 & $26,6 \pm 12,6 \mathrm{a} *$ & $13,6 \pm 5,6 \mathrm{a}$ & $26,3 \pm 12,6 \mathrm{a}$ & $23,6 \pm 14,2 \mathrm{a}$ & $5,0 \pm 1,2 \mathrm{a}$ & $4,8 \pm 2,5 \mathrm{a}$ \\
2 & $20,2 \pm 09,4 \mathrm{~b}$ & $13,6 \pm 3,7 \mathrm{a}$ & $23,4 \pm 15,4 \mathrm{a}$ & $23,3 \pm 10,6 \mathrm{a}$ & $6,7 \pm 2,2 \mathrm{a}$ & $4,5 \pm 1,8 \mathrm{a}$ \\
\hline
\end{tabular}

* Valores apresentados em grama/quilograma de matéria seca.

* Os valores seguidos da mesma letra minúscula na vertical não diferem entre si pelo Teste de Tukey ao nível de 5\% de significância. ${ }^{1}$ Amostras coletadas na região Sudoeste do Paraná. ${ }^{2}$ Dados fornecidos por Carneiro et al. (2004). Cama de aviário da região de Londrina (PR). AM = Amostras analisadas.



Figura 5. Composição química da cama de aviário obtida de 03 amostras da região Sudoeste do Paraná.

Comparando os valores obtidos neste trabalho com valores observados em cama de aviário da região de Londrina por Carneiro et al. (2004), verifica-se que os valores são semelhantes entre si, não diferindo estatisticamente pelo Teste de Tukey ao nível de 5\% de significância, corroborando os resultados obtidos.

As características nutricionais dos afluentes e dos efluentes obtidos dos processos fermentativos, sob condições anaeróbias utilizando os três tratamentos, T1 - cama de frango + biofertilizante oriundo de dejetos de aves + água, $(\mathrm{CF}+\mathrm{B}+\mathrm{A})$; $\mathrm{T} 2$ - cama de frango + biofertilizante oriundo de dejetos de aves $(\mathrm{CF}+\mathrm{B})$; e T3 cama de frango + água $(\mathrm{CF}+\mathrm{A})$, estão sumarizadas na Tabela 6. 
Tabela 6. Composição química do biofertilizante produzido de forma anaeróbica em um biodigestor, tendo como substrato cama de aviário. Valores calculados com base na matéria úmida*.

\begin{tabular}{ccccccc}
\hline \multirow{2}{*}{ Parâmetro } & \multicolumn{5}{c}{ Afluente } & \multicolumn{3}{c}{ Efluente } \\
\cline { 2 - 7 } & $\mathbf{C F + B + A}$ & $\mathbf{C F + B}$ & $\mathbf{C F}+\mathbf{A}$ & $\mathbf{C F + B + A}$ & $\mathbf{C F}+\mathbf{B}$ & $\mathbf{C F}+\mathbf{A}$ \\
\hline $\mathrm{N}(\mathrm{g} / \mathrm{L})$ & 9,21 & 12,53 & 8,45 & $15,02 \mathrm{~b}$ & $19,23 \mathrm{a}$ & $13,65 \mathrm{~b}$ \\
$\mathrm{P}(\mathrm{g} / \mathrm{L})$ & 11,08 & 20,12 & 15,95 & $15,04 \mathrm{~b}$ & $20,27 \mathrm{a}$ & $18,84 \mathrm{ab}$ \\
$\mathrm{K}(\mathrm{g} / \mathrm{L})$ & 8,46 & 9,32 & 5,89 & $14,26 \mathrm{a}$ & $15,01 \mathrm{a}$ & $10,43 \mathrm{~b}$ \\
$\mathrm{Ca}(\mathrm{g} / \mathrm{L})$ & 8,23 & 13,25 & 14,45 & $30,20 \mathrm{~b}$ & $38,76 \mathrm{a}$ & $39,25 \mathrm{a}$ \\
$\mathrm{Mg}(\mathrm{g} / \mathrm{L})$ & 6,68 & 10,56 & 9,53 & $15,99 \mathrm{~b}$ & $18,43 \mathrm{a}$ & $19,65 \mathrm{a}$ \\
$\mathrm{Na}(\mathrm{g} / \mathrm{L})$ & 11,21 & 9,24 & 8,20 & $15,00 \mathrm{a}$ & $11,98 \mathrm{~b}$ & $13,55 \mathrm{~b}$ \\
$\mathrm{Fe}(\mathrm{mg} / \mathrm{L})$ & 6,45 & 4,02 & 4,23 & $9,08 \mathrm{c}$ & $16,23 \mathrm{a}$ & $11,98 \mathrm{bc}$ \\
$\mathrm{Mn}(\mathrm{mg} / \mathrm{L})$ & 1,54 & 1,35 & 1,43 & $2,56 \mathrm{~b}$ & $5,02 \mathrm{a}$ & $4,99 \mathrm{a}$ \\
$\mathrm{Cu}(\mathrm{mg} / \mathrm{L})$ & 0,56 & 0,96 & 1,02 & $1,02 \mathrm{~b}$ & $3,67 \mathrm{a}$ & $2,56 \mathrm{ab}$ \\
$\mathrm{Zn}(\mathrm{mg} / \mathrm{L})$ & 4,32 & 4,56 & 3,98 & $8,79 \mathrm{~b}$ & $13,65 \mathrm{a}$ & $9,86 \mathrm{~b}$ \\
$\mathrm{pH}(\mathrm{CaCl})$ & 6,58 & 6,76 & 6,66 & $7,81 \mathrm{a}$ & $8,02 \mathrm{a}$ & $7,98 \mathrm{a}$ \\
\hline
\end{tabular}

* Valores representados pelas médias de oito amostras.

${ }^{2}$ Médias seguidas da mesma letra minúscula na horizontal não diferem entre si, pelo Teste de Tukey ao nível de $5 \%$ de significância.

Analisando-se os dados contidos na Tabela 8 verifica-se que, de modo geral, os tratamentos diferiram estatisticamente entre si para os teores de macro e micronutrientes nos efluentes avaliados. Os teores de nitrogênio e fósforo observados para o tratamento $\mathrm{CF}+\mathrm{B}$, foram os que tiveram os maiores resultados, diferindo estatisticamente dos tratamentos $\mathrm{CF}+\mathrm{B}+\mathrm{A}$ e $\mathrm{CF}+\mathrm{A}$. Comparando o afluente com o efluente, os teores de micronutrientes na saída foram os que apresentaram mais variações em comparação ao material afluente, principalmente o cobre e o zinco.

Os teores de $\mathrm{N}$ e $\mathrm{P}$ foram os mais significativos para o tratamento $\mathrm{CF}+\mathrm{B}$, observando-se maiores valores no efluente em relação aos demais nutrientes, o que evidencia que os minerais ficaram muito mais concentrados nesse tipo de tratamento e que a matéria orgânica saiu na forma de biogás. É importante considerar que o aumento da concentração de nutrientes pode contribuir para o aumento da produção de biogás, pois oferece um meio mais propício ao desenvolvimento dos microrganismos anaeróbios, assim como permite a obtenção de um efluente com maior 
concentração de elementos fertilizantes.

Portanto, esse tipo de associação da cama de frango + biofertilizante é de grande importância para o produtor que trabalha além da criação de aves e/ou bovinos, com sistemas de integração lavoura-pecuária, minimizando os custos com fertilizantes químicos, utilizando assim o biofertilizante como uma fonte alternativa na propriedade.

No que diz respeito à composição química, o biofertilizante apresentou macro e micronutrientes assimiláveis pelo vegetal, tais como: nitrogênio, fósforo, potássio, cálcio, magnésio, sódio, ferro, boro, cobre, zinco e manganês. O seu pH pode variar de 6,6 a 8,0, sugerindo com isso que o processo de fermentação foi adequado, pois índices de $\mathrm{pH}$ inferiores são indicativo de fermentação incompleta (SANTOS, 1992).

Deve-se destacar que a composição, a quantidade e as características da cama de frango variam de acordo com o material, densidade, duração do ciclo, número de lotes criados, tempo de armazenagem, além de técnicas de manejo das aves, fatores ambientais e fisiológicos. Estas variações irão conferir diferentes concentrações de macro e micronutrientes nas camas, o que tem influência no processo de biodigestão anaeróbia e na qualidade do biogás e do biofertilizante.

\section{CONSIDERAÇÕES FINAIS}

Após a realização deste trabalho, com os dados obtidos pode-se concluir que as amostras de cama de aviário produzidas na região Sudoeste do Paraná são constituídas de nitrogênio $(26,60 \pm 12,60 \mathrm{~g} / \mathrm{kg})$; fósforo $(13,60 \pm 5,67 \mathrm{~g} / \mathrm{kg})$; potássio $(26,30 \pm 12,67 \mathrm{~g} / \mathrm{kg})$; cálcio $(23,60 \pm 14,21 \mathrm{~g} / \mathrm{kg})$; magnésio $(5,07 \pm 1,23 \mathrm{~g} / \mathrm{kg})$; e sulfato $(4,85 \pm 2,54 \mathrm{~g} / \mathrm{kg})$.

$\mathrm{O}$ processo de biodigestão anaeróbia foi eficiente em produzir biogás no Ensaio 3 e os três tratamentos avaliados produziram volumes de biogás diferentes, sendo que o melhor tratamento foi aquele em que se utilizou cama de frango associada ao biofertilizante $(\mathrm{T} 2-\mathrm{CF}+\mathrm{B})$, sugerindo que o biofertilizante atuou como sistema que ativou o processo, seguido do tratamento em que se utilizou cama de frango associada ao biofertilizante mais água $(\mathrm{T} 1-\mathrm{CF}+\mathrm{B}+\mathrm{A})$. Os menores valores 
foram observados no terceiro tratamento, cuja mistura foi cama de frango e água (T3 - $\mathrm{CF}+\mathrm{A})$.

O biofertilizante apresentou macro e micronutrientes assimiláveis pelos vegetais, tais como: nitrogênio, fósforo, potássio, cálcio, magnésio, sódio, ferro, boro, cobre, zinco e manganês. O seu $\mathrm{pH}$ pode variar de 6,6 a 8,0, sugerindo com isso que o processo de fermentação foi adequado, pois índices de $\mathrm{pH}$ inferiores promovem a fermentação incompleta, uma vez que permite a geração de ácidos capazes de inibir o processo fermentativo.

Os teores de macro e micronutrientes dos biofertilizantes produzidos diferiram estatisticamente entre si nos efluentes avaliados em relação ao afluente do sistema. Os teores de nitrogênio e fósforo foram os que tiveram os maiores resultados, no tratamento $\mathrm{CF}+\mathrm{B}$, diferindo estatisticamente dos tratamentos $\mathrm{CF}+\mathrm{B}+\mathrm{A}$ e $\mathrm{CF}+\mathrm{A}$.

A utilização da cama de aviário como fertilizante é desejável economicamente, uma vez que representa um recurso interno da propriedade rural e é um resíduo contendo elevada concentração de nutrientes.

O uso da cama de aviário na agricultura é limitado pelos níveis de nitrogênio contidos nesta cama e pelas características físico-químicas e de conservação de cada solo.

\section{REFERÊNCIAS}

\section{AIRES, A.M.A. Biodigestão anaeróbia da cama de aviários de corte com ou} sem separação das frações sólida e líquida. 2009. 134f. Dissertação (Mestrado em Zootecnia) - Universidade Estadual Paulista, Faculdade de Ciências Agrárias e Veterinárias, Jaboticabal, 2009.

ASSOCIAÇÃO DOS MUNICÍPIOS DO SUDOESTE DO PARANÁ. AMSOP. Dados gerais dos municípios. Disponível em: $<$ http://www.amsop.com.br/aspec_pop_censitaria.php>. Acesso em: 08 set. 2010.

BATAGLIA, O. G. Métodos de análises químicas de plantas. Campinas: Instituto Agronômico, 1983. 48p. 
CARNEIRO, S.L.; ULBRICH, A.C.; FALKOWSKI, T.; CARVALHO, C.; SOARES JR, S.; LLANILLO, R.F.F. Frango de corte: integração produtor/indústria. Curitiba: Programa Paraná 12 meses, 2004.

COSTA, L. V. C. Produção de biogás utilizando cama de frango diluída em água e em biofertilizante de dejetos suínos. 2012. 75f. Tese (Doutorado) - Faculdade de Ciências Agronômicas, Botucatu, SP, 2012.

DIEDRICH, C.; ROCHA, R.D.C.; LOPES, C.A. Produção de biogás a partir de produtos agroindustriais. In: SEMINÁRIO DE INICIAÇÃO CIENTÍFICA E TECNOLÓGICA DA UTFPR, 17., 2012. Anais... Pato Branco: UTFPR, 2012.

MAGALHÃES, A.T.P. Biogás: um projeto de saneamento urbano. São Paulo: Nobel, 1986. 120p.

MALAVOLTA, E.; VITTI, G.C.; OLIVEIRA, S.A. Avaliação do estado nutricional das plantas: princípios e aplicações. 2. ed. Piracicaba: Potafos, 1991. 319p.

ORTOLANI, A.F.; BENINCASA, M.; LUCAS JUNIOR, J. Biodigestores rurais: modelos Indiano, Chinês e Batelada. Jaboticabal: FUNEP, 1991. 3p.

SANTOS, A.C.V. Biofertilizante líquido, o defensivo da natureza. Niterói: EMATER/Rio, 1992. 16p.

SEIXAS, J. Construção e funcionamento de biodigestores. Brasília: EMBRAPA/ DID, EMBRAPA/CPAC, 1980. (Circular técnica 4).

SERVIÇO BRASILEIRO DE APOIO ÀS MICRO E PEQUENAS EMPRESAS. SEBRAE. Cadeia produtiva da avicultura: cenários econômicos e estudos setoriais. Sebrae, 2008. Disponível em: < http://177.52.17.17:8030/downloads/avicultura.pdf $>$. Acesso em: 14 mai. 2014.

SILVA, D.J. Análise de alimentos: métodos químicos e biológicos. Viçosa: Ed. da UFV, 1983. 166p.

SILVA, F.M.; LUCAS JÚNIOR, J.; BENINCASA, M.; OLIVEIRA, E. Desempenho de um 
aquecedor de água a biogás. Engenharia Agrícola, Jaboticabal, v. 25, n. 3, p. 608$614,2005$.

SUZUKI, A.B.P.; FEIDEN, A.; FERNANDES, D.M.; MARTINS, G.I.; FARIA, R.A.P. Utilização de manipueira juntamente com sólidos da cama de aviário em biodigestores para geração de biogás. Ambiência Guarapuava (PR), v. 8, n. 3, p. 809-820, set./ dez. 2012.

Recebido em: 07 de outubro de 2013 Aceito em: 22 de maio de 2014 